\section{What is News?}

News is factual information about current events. News is reported by a variety of sources, such as newspapers, magazines, television shows, cable and radio programs, Web sites, email messages, and word of mouth.

What makes an event worthy of being in the news? Journalists look for stories that answer one or more questions:

-When did the event happen?

- Where did the event occur?

- How many people were, are, or will be affected?

- Is the information brand new?

- Was the event unusual?

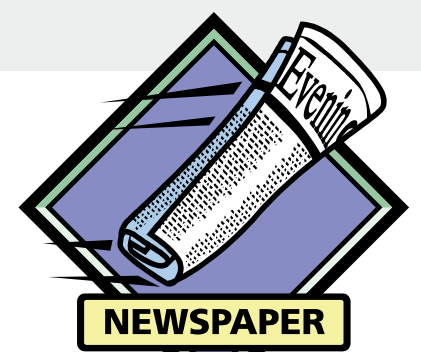

\section{Sections of a Newspaper}

Newspapers usually have several sections. Below are some examples and what you can find in each one.

1. International: The International section tells you about news in other countries, such as Germany, Russia, or Brazil.

2. Regional: The Regional section covers events in your city and the areas surrounding it.

3. Business: The Business section includes local, state, national, and international business news. Reports on media, advertising, world business, the local economy, or the stock markets may appear in this section.

4. Science/Technology: The Science and Technology section often focuses on advances in medicine, space, computers, agriculture, and cars. This section may also cover environmental news or technology updates.

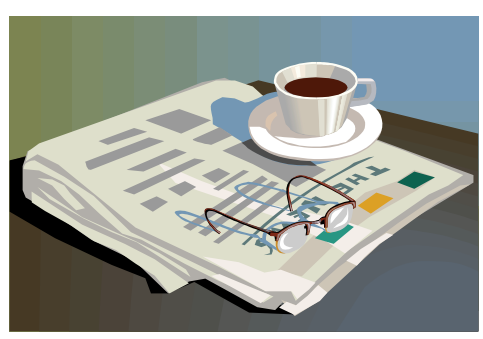

5. Health: The Health section usually contains information relating to human health. There might be news about fitness and nutrition, health care, and mental health and behavior.

6. Sports: In the Sports section, you can find out about baseball, basketball, golf, soccer, tennis, football, and other sports you enjoy watching.

7. Weather: The Weather section is where you can find information about the weather in your region and across the world.

8. Editorial: The Editorial section contains articles or statements that express an opinion or point of view. Letters to the editor, columns, and political cartoons often appear in this section.

\section{Types of News Articles}

1. News Article: An article about a current event. This type of article reports the facts of the event, with no opinions of the reporter.

\section{Feature Story: A longer, more} detailed story on a person, an issue, or an event. This type of article may use some creative writing, making it more entertaining to read.
3. Column: A piece of writing that contains the writer's personal views on a topic. The column is a regular feature of the newspaper, but may not always be written by the same person.

\section{Editorial: An article in which} journalists give their opinion on an important issue.
5. Advertisement: A paid message in magazines or newspapers promoting products, store sales, and business grand openings.

6. Graphics \& Captions: Visual elements (photos, clip art, graphs, or cartoons) added to the text to make it more interesting or easier to understand. 


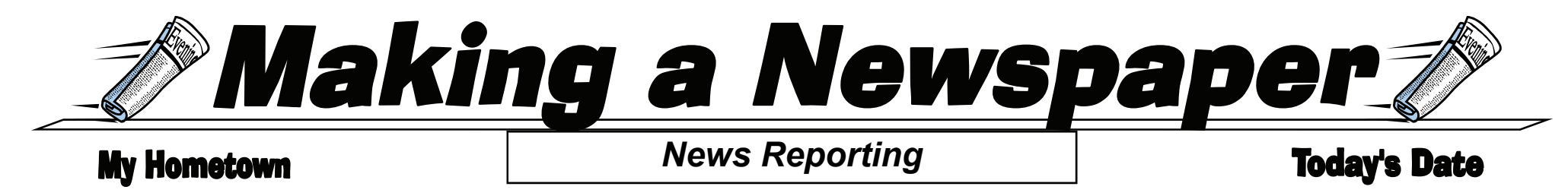

So, what is a NEWS ARTICLE?

It is an article about some current event. This type of article reports the facts of the event; the reporter does not include his/her opinions. You will need to research your topic in order to find out the facts.

Two major types of articles that are in this category are:

1.General News Reports these are shorter articles that report on the facts of recent events, usually within a short period of time.

2. Investigative Reports - these are longer and more detailed articles that require more research. These may show up in a newspaper in installments or as a series of articles.

\section{Investigative Reporting}

Investigative Reports are different from General News Reports.

1. These reports are longer and much more detailed.

2. The reporters research the topic in greater depth. They will:

- use computer databases

- conduct extensive interviews

- seek out and review piles of documents

3. Gathering information usually takes several weeks.

4. These reports often include data from studies or research that has been performed.

\section{News Reporting}

The structure of a news story is often called the "inverted pyramid." That is because the main, and most important, point is contained in the first sentence. The rest of the story contains elements of less importance as the reader nears the bottom.
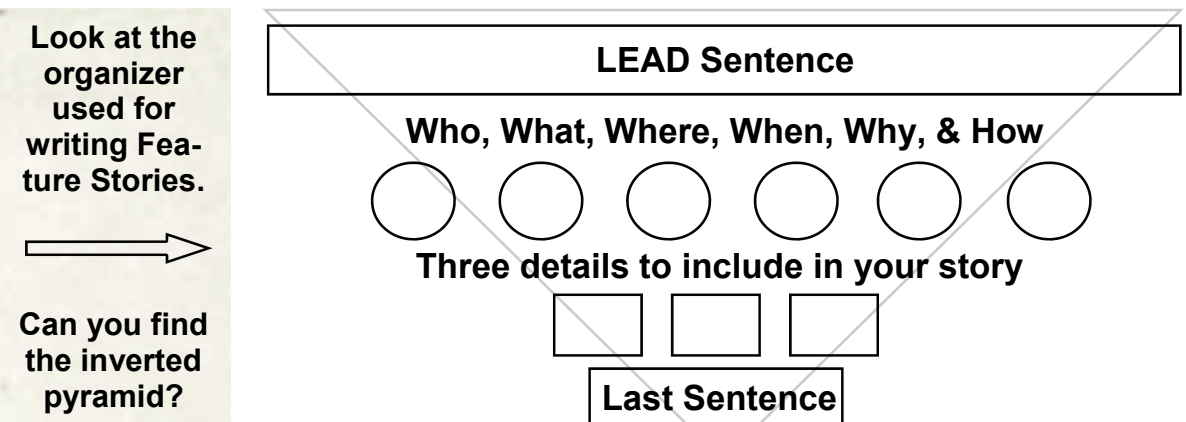

Three details to include in your story

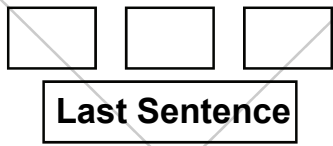

\section{Parts of an Article}

The first paragraph in a news article is called the LEAD. The lead must summarize the basic facts of a story and convey to a reader what you are reporting. But it is more than just the beginning of your story. The lead needs to "catch" the reader's attention and make them want to read the rest of your story.

The rest of the paragraphs are referred to as the BODY. The body of the article supports the story told in the lead by including details such as facts, examples, or quotes. The body should be organized so that it is easy to read and understand.

And, finally, as with any good story, there should be an ENDING that is short, direct, and memorable. You do not need to repeat everything from the body of your article. Simply make a statement that "wraps up" your thoughts on the topic.

Don't forget to include GRAPHICS, which help make the story more interesting and understandable.

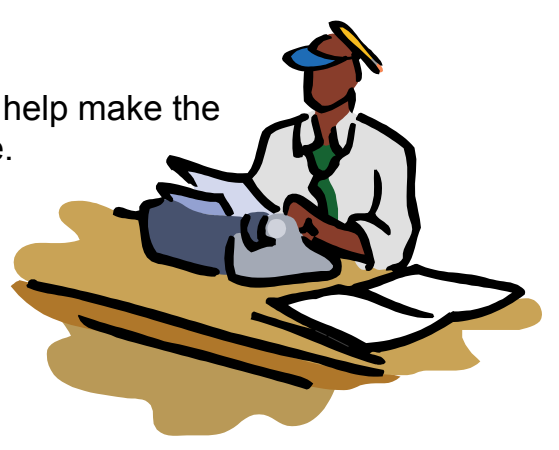




\section{Headline}

The HEADLINE describes the main point of the story. It is usually in bold and in a larger font than the story.

\section{To write a headline:}

- Keep it Simple -

A headline is a short, direct sentence without extra adjectives or adverbs.

- Give Information -

The headline tells your reade what the article is about.

\section{- News Now -}

Be sure to use active voice when writing your headlines.

\section{Body}

The BODY is the main story.

- Answer Questions -

Remember to answer the questions Who?, What?, Where?, When?, Why? and How? in the body of your article. These answers give your reader the most important information about your topic.

\section{- Be Detailed -}

Use specific details about the topic. Details make your topic easier to understand.

\section{Ioning your way to cleaner clothes}

By Julie Clothier for CNN

Designers behind a washing machine that does not require water or detergent to clean clothes say the idea could be a common household appliance one day.

The idea is the brainchild of two Singaporean design students who won top honors at the recent International Electrolux Design Lab awards in Stockholm for their "Airwash" washing machine.

National University of Singapore industrial design students Gabriel Tan and Wendy Chua's prototype uses negative ions, compressed air and anti-bacterial deodorants to clean clothes.

The unit uses no water or detergents, and can be placed in any room of a home. Clothing is placed on a rack, which slides inside the device.

"It's a bit like a car wash," Tan told CNN. "The clothing goes on a rack which is placed inside the machine. The clothing then gets a good blast. It's a substitute for taking items to the dry cleaner."

He said the cleaning process was much gentler on clothes than conventional methods, and was particularly useful for expensive clothing that could lose its shape and color through washing with water and detergents.

By using atmospheric air and negative ions, a natural

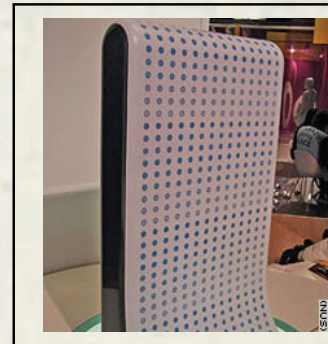

The "Airwash" cleans clothes without water or detergent and can be placed in any room of the home. cleansing agent, it fights dirt and bacteria with nature's own weapon, he said.

The Airwash cleans one piece of clothing at a time, with each item taking between three and 12 minutes to complete the process.

"In a poetic sense, we are using nature's weapons, nature's cleansing agents, to solve a problem," Tan said.

Chua told CNN that she and Tan had taken technology and processes commonly used in air conditioning and air purifying units and adapted it for an alternative use.

At this stage the Airwash is a concept prototype but she believed it could one day become a commercial reality.

"Our dream would be to see it on the market one day, not for personal pride, but because we genuinely believe it will be good for the environment and have a positive impact on the lives of people -- be it as a consumer product or as a replacement for today's commercial dry cleaners."

Judges at the competition said the "Airwash" won the award because of: "its intuitive, ecological and beautiful design. Airwash also does away with the expensive, time-consuming task of going to the dry cleaner."

The competition is organized annually by the Electrolux Group and aims to encourage students from around the world to design household appliances for the future.

This year, participants competed to create the most outstanding new appliance concept for the home of 2020 .

\section{Byline}

The BYLINE tells who wrote the story.

\section{Graphic} GRAPHICS help make the story more informative or interesting.

\section{Baption}

CAPTIONS give important information about the graphics in the story. This is sometimes called a "cutline." 
So, what is a FEATURE STORY? It may be...

1.a story about one person or a group (an athlete, an actor, a politician, a team, a choir, or a school organization)

2. an in-depth look at a current social issue (violence in American schools or eating disorders among teenagers)

3. a story giving background on a topic that's in the news -- like a story that explains how vaccines work and the history of their use.

A feature story is usually longer than a news story.

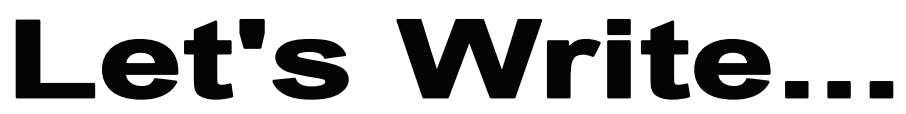

You have been assigned to write a FEATURE STORY for your newspaper. Before you start writing, remember to:

$\checkmark$ Collect information for your stories. Do some research.

- Encyclopedias, dictionaries, or other reliable sources are great places to find facts.

- The Internet can be a valuable source of information. Make sure you choose reliable sites that are up-to-date and give you facts, not just someone's opinion.

- Interview someone who knows the topic you are writing about. $\square$ Answer six questions: Who? What? Where? When? Why? \& How?

- Usually you answer these in the first sentence of the story, which is called the "lead."

$\checkmark$ Be accurate.

- Using false information will cause your readers to lose trust in what you write. It is also against journalism's "Code of Ethics."

Make stories interesting.

- Write creatively and answer questions that you think your readers might have about your subject.

\section{ORGANIZING YOUR INFORMATION}

Plan your story following the organizer below:

\section{Lead Sentence}

Who, What, Where, When, Why, \& How

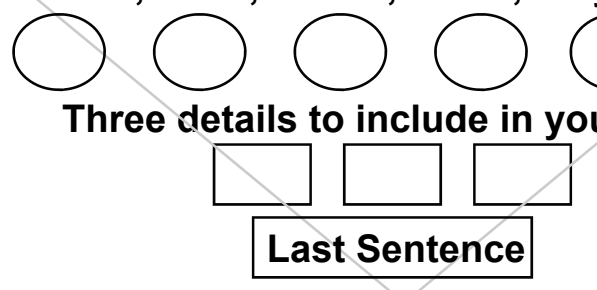

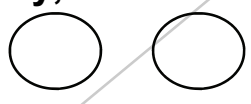

your story

\section{Today's Feature Story}

This is a real-life Feature Story you can follow as an example when writing yours.

\section{World's report on global warming: "Must try harder"}

\section{By Alister Doyle}

HELSINKI, Nov 1, 2006 (Reuters) - More than a decade after world leaders pledged to avert "dangerous" climate change, a report card on their efforts so far might read: "Must try harder".

Rising industrial emissions of greenhouse gases, acrimony between Washington and many of its allies over policy and a report this week that the world economy risks a 1930s-style

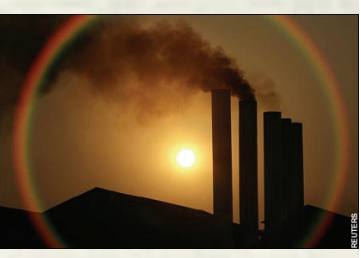

Depression by failing to act are among reasons for gloom.

Yet some see hope in widening concern that the use of fossil fuels is stoking global warming -indicated by billions of dollars invested in "clean coal", wind or solar energy or by campaigns to get people to turn off unnecessary lights at home.

"Of course, we must try harder," said Finland's Environment Minister Jan-Erik Enestam, whose country holds the rotating presidency of the European Union.

"What we have in place at the moment is nothing more than a very modest start," said Yvo de Boer, head of the United Nation's Climate Change Secretariat in Bonn.

Even so, he added: "I think we've achieved a great deal."...

Source:

http://www.reuters.com 

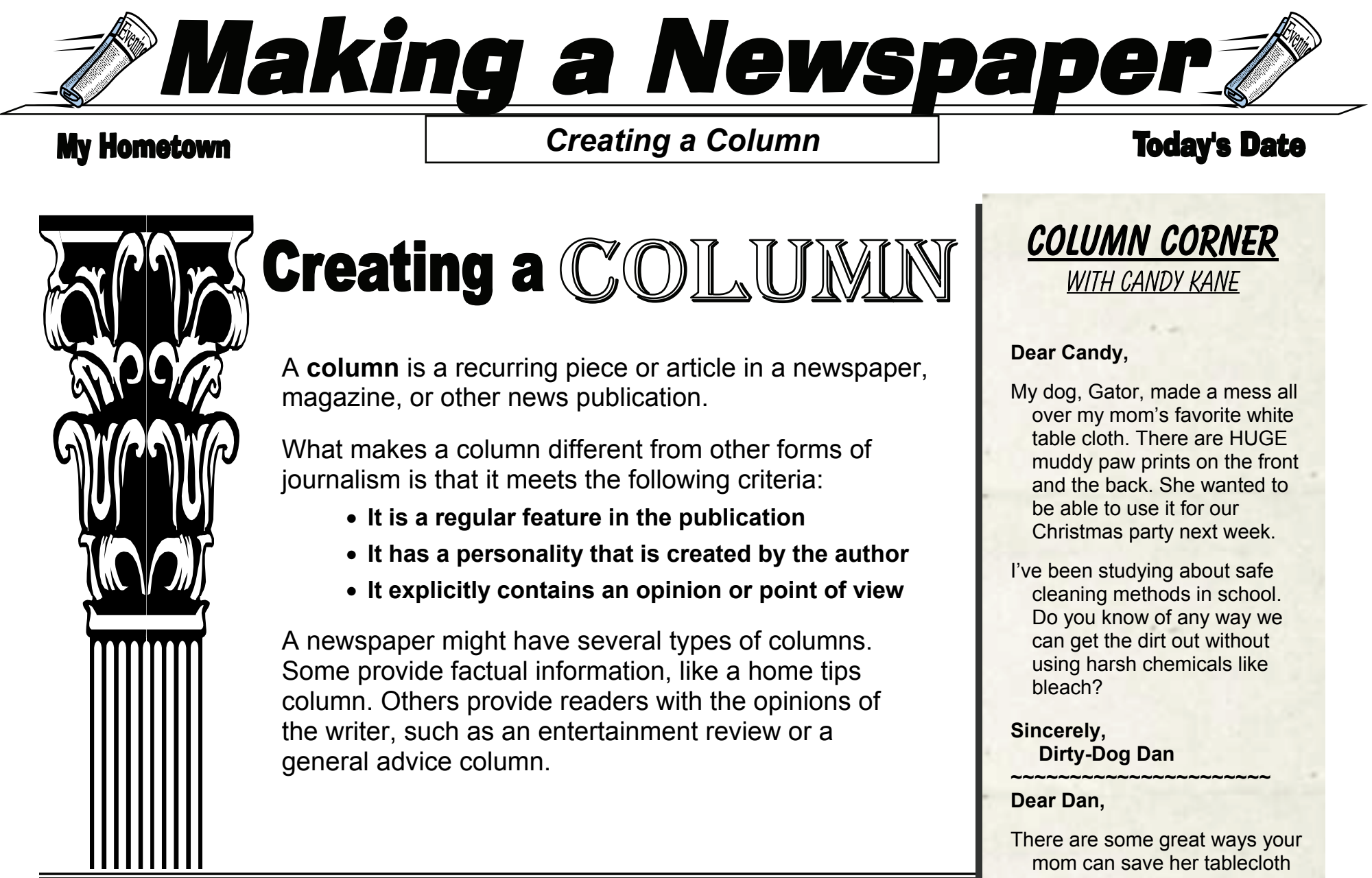

\section{Creating a
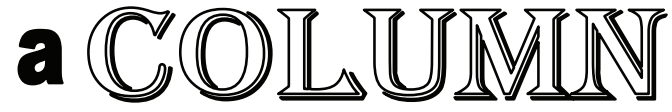

A column is a recurring piece or article in a newspaper, magazine, or other news publication.

What makes a column different from other forms of journalism is that it meets the following criteria:

- It is a regular feature in the publication

- It has a personality that is created by the author

- It explicitly contains an opinion or point of view

A newspaper might have several types of columns. Some provide factual information, like a home tips column. Others provide readers with the opinions of the writer, such as an entertainment review or a general advice column.

\section{Just the Facts, Please}

You've been assigned to write a HEALTHY HOMES COLUMN for your newspaper. Keep the tips below in mind while planning your column:

$\square$ Columns usually take on the personality of the writer. So be creative!

$\checkmark$ The information in this column is based on solutions that you have tried out and have an opinion on, or information that is based on facts.

- Remember, you are giving someone advice. Be a source of reliable information.

$\checkmark$ You will need to have basic information in order to answer the questions. So you will need to do research! $\checkmark$ The normal format of advice columns is question/answer.

- Usually someone asks a question that the columnist answers. (See samples in Column Corner)

- There are TWO parts of a column: The QUESTION

1.Dear ...(fill in your name)

2. The Question/Problem

3. Signed By....(whoever is asking the question) Full names are usually not used. Instead, the first name and initial of the last name or a made-up name may be used.

\section{The ANSWER}

1.Dear ...(whoever is asking the question)

2. The Answer

3. Signed By...(create your own pen name)
COLUMN CORNER

WITH CANDY KANE

Dear Candy,

My dog, Gator, made a mess all over my mom's favorite white table cloth. There are HUGE muddy paw prints on the front and the back. She wanted to be able to use it for our Christmas party next week.

l've been studying about safe cleaning methods in school. Do you know of any way we can get the dirt out without using harsh chemicals like bleach?

Sincerely, Dirty-Dog Dan

\section{Dear Dan,}

There are some great ways your mom can save her tablecloth without using harsh chemicals. It depends on what type of material the tablecloth is made of.

If it is a natural material, like cotton, she can use one of my favorite methods. Boil the tablecloth in water, adding a little soap powder and fresh lemon. Let it simmer for 10 minutes. The lemon acts like a bleaching agent.

If her tablecloth is made from a synthetic (or man-made) material, then she should look for a bleach at the store containing the ingredient percarbonate. This ingredient contains soda and oxygenated water, so it is entirely natural. Follow the directions on the packaging to get you tablecloth spotless.

I hope these tips will help you and your mom fix Gator's dirty dilemma.

Best Wishes, Candy Kane 
Creating a Colum

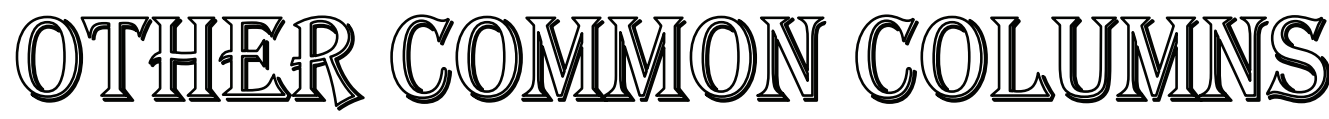

\section{Entertainment Reviews}

Critics working for newspapers, magazines, or other publications review movies, plays, restaurants, operas, ballets, music concerts, art shows, and other local entertainment events. Then critics share their opinions with their readers. They might use a rating scale, like the one below, to grade the overall show or the actors in the show.
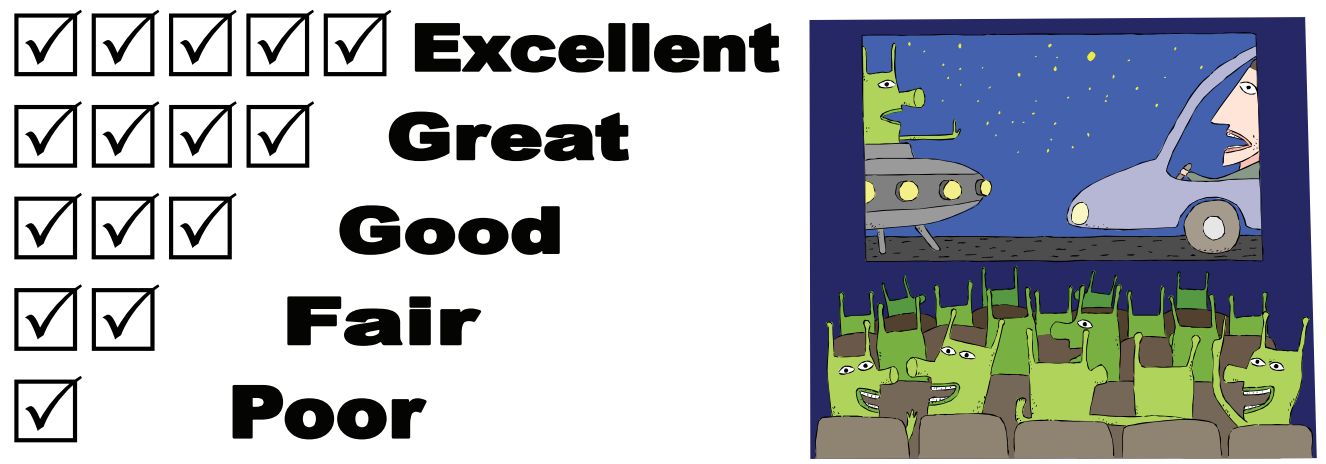

\section{AT THE MOVIES WITH MOVIE MAX}

Dear Readers,

I went to see the latest sci-fi movie "My Mom's From Mars?". This move stars two new actors: A. Leon and Rock Kettoo-Moon.

The non-stop action of this movie had me on the edge of my space seat throughout most of the 4 hours. Add that to the wonderful alien/earthling humor, and I have to give this movie 4 thumbs way up!
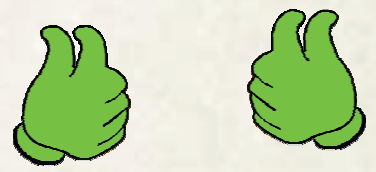

If you haven't already seen this movie, I would definitely recommend seeing it with your favorite Martian mom

Until the Next Flick, Movie Max

\section{Advice Columns}

ADVICE COLUMNS offer advice to readers of the newspaper or magazine regarding some personal problem. These columns are based on the writer's personal opinions. Usually, the writer has education and experience that makes the columnist a reliable source of advice. He or she may be a licensed doctor, a mental health therapist, or a psychologist.

$\checkmark$ Columns usually take on the personality of the writer. Be creative.

$\checkmark$ The normal format of advice columns is question/answer.

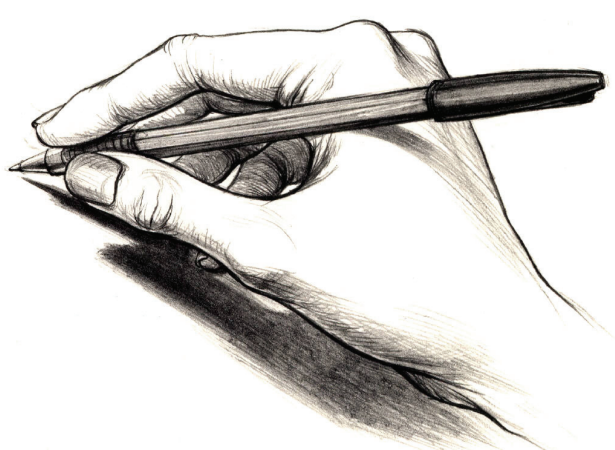

\section{LIFE LESSONS WITH HELPFUL HILARY}

Dear Helpful Hilary,

I am going to a new school this year and I am afraid I won't find any friends. I had so many friends at my old school. Do you have any suggestions?

Sincerely, Lonely Lucy

Dear Lonely Lucy,

I know that going to a new school can be scary. It sounds like you were able to build friendships at your last school, which means you must be someone who attracts friends. Be outgoing; smile when someone smiles at you, and, most important, be yourself.

Best Wishes, Helpful Hilary 


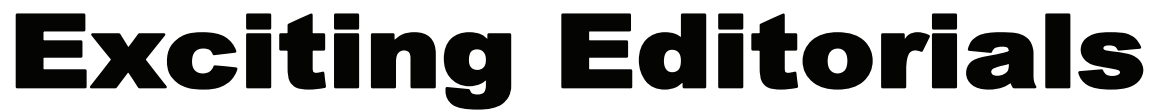

An editorial is a statement or article by a news organization, newspaper or magazine that expresses the opinion of the editor, editorial board, or publisher. The topics covered by an editorial are usually current events or public controversy. Often times readers contribute editorials or letters to the editor to their local newspapers.

\section{Parts of an Editorial}

An EDITORIAL has 4 main parts:

- An opinion.

There is usually one simply stated sentence in an editorial that expresses the author's opinion. This sentence is similar to a topic sentence, since the rest of the piece supports that opinion.

- Reasons for the opinions.

The author must also have reasons for why he or she has that opinion about that specific topic.

- Facts to support the opinions.

Many editorials supply facts on the issue at hand. The more facts you have to support your opinions and reasons, the more accurate and credible your editorial will be.

- Suggestions for dealing with the topic.

Another part of editorials are suggestions. Some authors not only have opinion on a subject, but they also have ideas for how to improve the situation.

\section{Position of an Editorial}

Editorials usually have one of three positions:

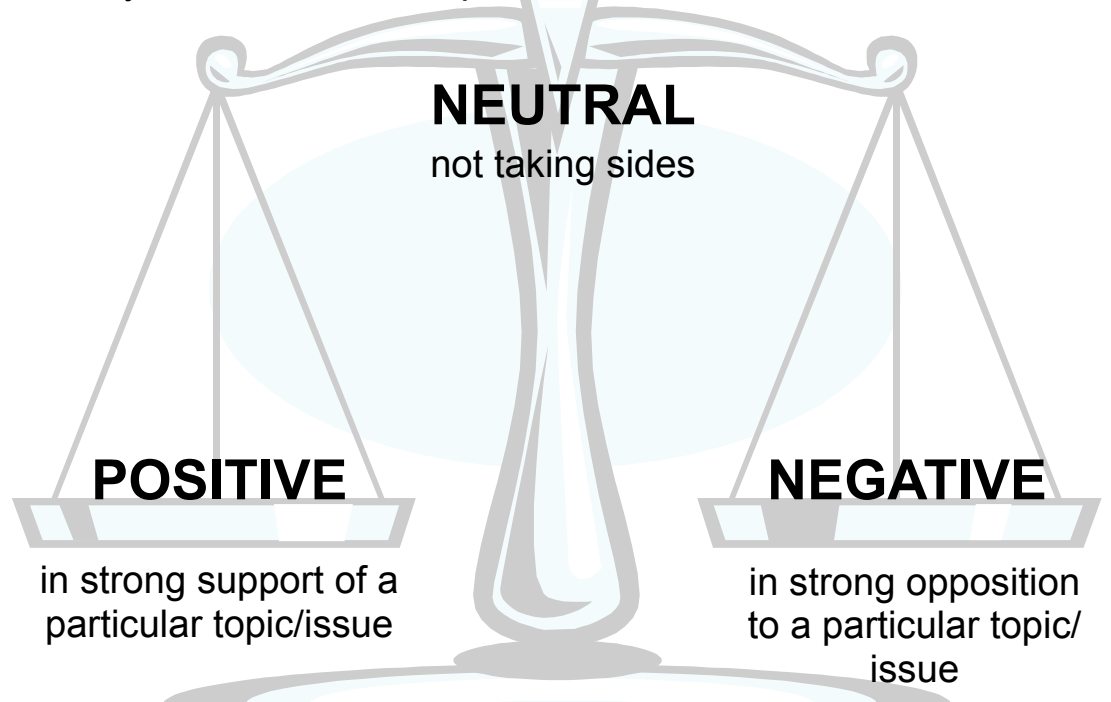

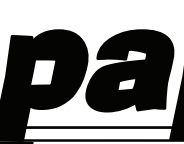

per

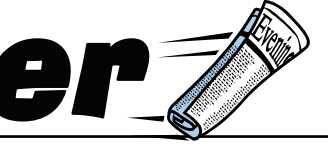

Today's Date

\section{MORNING}

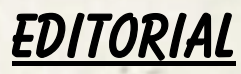

TODAY'S TOPIC: A New Time for School to Start in the Morning (7:00 a.m.)

\section{POSITIVE}

I think that it would be great for school to start at 7:00 a.m. Since school lasts for 7 hours each day, that means I would be able to get out of school by 2:00 in the afternoon. I would have $\mathbf{2}$ more hours every afternoon to play soccer before I had to do my homework and go to bed. To make it easier for kids to change to the new time, the school should wait until next year. This way, we have the whole summer to sleep before we start school.

-Early Bird Bobby

\section{NEUTRAL}

Kids have always argued over what time school should start. Some kids want school to start earlier so they have more time after school to do sports and other fun activities. Other kids like sleeping in the morning, so starting school earlier would be difficult for them. Maybe the school could just stay the time it is now, since everyone is already on that schedule. -No Position Nancy

\section{NEGATIVE}

I hate the idea of school starting at 7:00 a.m. I already have a hard time getting up in the morning and then getting to school by 8:30. My mom would make me get up at 5:30 a.m. Our rooster isn't even up that early! The school should make two schedules so that kids who want to sleep in can just come in later.

-Sleep in Susanna 


\section{Making a News \\ Using Graphics \& Advertising}

My Hometown

Graphics are visual elements

that are added to printed

information to make the

messages more interesting or

understandable. A graphic can

be a photo, a drawing, or a

piece of clip art that

represents the story.

It can also be a chart,

graph, or table that

shows data related to

the article's topic.

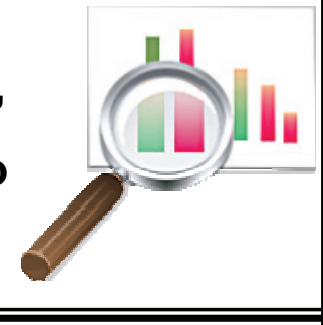

Create an Awesome Ad

Companies promote their products by advertising. Ads are messages in magazines, newspapers, on radio stations, or other media sources that encourage people to use, buy, or become loyal to a specific product. Advertisers want products to "stand out" in your mind so they look for ways to attract your attention and get you interested in buying their product

\section{Parts of an Ad}

Theme: This is the ad's concept. It shows that the product has some functional, sensory, or symbolic benefits for the reader.

Copy: This is the printed information of an ad. Good copy should...

$\checkmark$ be interesting to read

$\checkmark$ capture the reader's attention

$\checkmark$ use simple words and phrases

$\checkmark$ be believable

Visual Cues: This is the graphic part of an ad.

Visual cues make an ad effective by...

$\checkmark$ attracting attention

$\checkmark$ communicating messages quickly

$\checkmark$ making information easier to remember

\section{Get Great Graphics}

Graphics are meant to enhance text, so be sure you choose graphics that tell the same story as your article. You wouldn't want to use a picture of a bluebird if you are writing an article about bumblebees.

Also, try to show the heart of the story with the picture you choose to use. The picture can answer a number of important questions (who, what, when, where, why, and how).

Remember, they say "a picture is worth a thousand words".

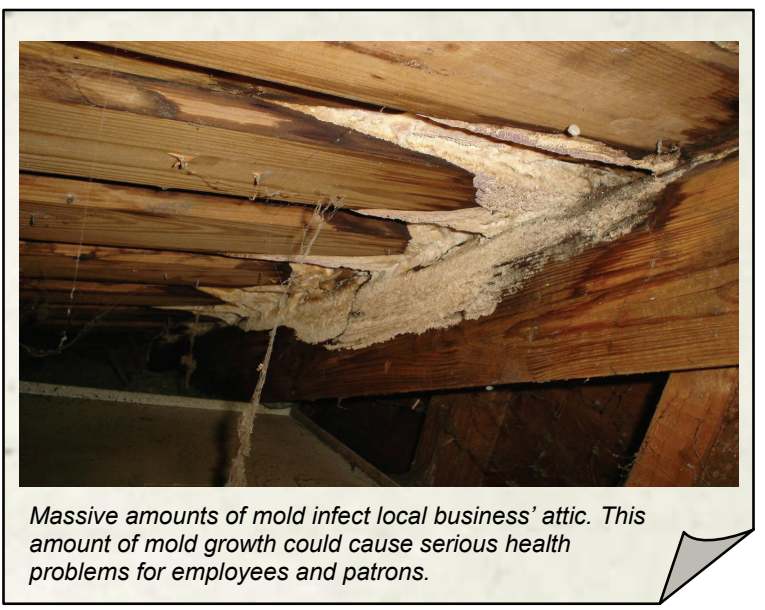

\section{Catchy Captions}

A caption is one or more sentences that summarizes the importance of photos, drawings, charts, graphs, or tables.

Captions identify the people in photographs and relate the photo or graphic item to the surrounding body copy. 
